\title{
A Literature Review of How Industry 4.0 Developments Achieving Strategic Objectives of Supply Chain Management
}

\author{
U.J. Mirando ${ }^{1}$, A. Fernando ${ }^{2}$ \& K.L.D.S. Perera ${ }^{3}$ \\ ${ }^{1}$ Department of Marketing Management, Faculty of Commerce \& \\ Management Studies, University of Kelaniya \\ SRI LANKA \\ ${ }^{2,3}$ Department of Industrial Management, Faculty of Science, \\ University of Kelaniya \\ SRI LANKA \\ uditha.mirando.95@gmail.com ${ }^{1}$, anushikafernando4@gmail.com ${ }^{2}, \&$ \\ dineshaperera617@gmail.com ${ }^{3}$
}

\begin{abstract}
In 21 century, the fourth industrial revolution has influenced the way that modern business is continuing. These days' Supply Chain Management (SCM) is playing a vital role and higher completive area. Therefore, worth exploring how techniques of Industry 4.0 utilization in the process of supply chain \& the role of Industry 4.0 on achieving strategic objectives of SCM. The study presented in this paper reviews recent literature in Industry 4.0 and SCM to link the effects of Industry 4.0 on strategic objectives of supply chain management. Within this study, 30 different articles based on the study area were reviewed, through which the aspects of quality improvement, the efficiency of supply chains, optimization of logistics \& distribution are found to be heavily impacted due to the developments of industry 4.0. The findings of this study explored that quality improvement, the efficiency of supply chains, transport, and logistics are heavily impacted due to the developments of industry 4.0 concepts within supply chains in the modern age. After achieving objectives of quality enhancement and optimization of logistics and distribution, it will lead to achieve the third objective of efficiency. Further, using the proposed model of this study indicated the linkage between the strategic objective of the supply chain in the industry 4.0 era. Future research suggested to consider other strategic objectives such as the leadership of SCM. And conduct the study concerning specific industries such as apparel, fast food.
\end{abstract}

Keywords -: Efficiency, Industry4.0, Optimization of Distribution Channels, Optimization of Logistics Routines, Strategic Objectives, Quality, Supply Chain Management, 


\section{INTRODUCTION}

A Supply Chain is a set of three or more entities (organizations or individuals) directly involved in the upstream and downstream flows of products, services, finances, or information from a source to a customer. Measuring organizational performance from the perspective of supply chain, logistics \& distribution is a challenging task. There are several criteria \& indicators currently used to measure and analyze flexibility, reliability, responsiveness, quality and asset management, efficiency, quality, performance improvements, innovation, time, price, and availability. In the contemporary business environment, there is competition among different supply chains between industries. A high level of integration among players in the supply chain is identified as a crucial factor in increasing the overall performance of the supply chain. Hence the organization at present, sharing the right information among the right players in the supply chain process at the right time will increase supply chain performance in terms of responsiveness, cost, quality, service delivery, and optimize logistic functions (Strandhagen et al., 2017).

However, business firms always attempt e-business solutions, innovation technologies, process integration \& analytical capabilities (Fatorachian \& Kazemi, 2021). Technologies \& concepts enabled by Industry 4.0 lead to a collaboration of the critical indicators effectively, execute effective communication flow from the point of origin to the point of consumption, and increase the overall organizational performance. The foundation of Industry 4.0 is about the transformation of modern supply chains into intelligent supply chains, employing various cuttingedge and disruptive technologies such as Cyber-Physical Systems, the Internet of Things, Cloud Computing, Virtual Reality, Simulation, 3D-printing, Big Data Analytics, Cloud Technologies, Cyber Security, Radio Frequency Identification (RFID), Machine to Machine Communication (M2M), Automatic Identification and Data Collection (AIDC), Robotics, Drones, Nanotechnology and Business Intelligence (BI) (Carvajal Soto et al., 2019). These developments imply drastic improvements of existing supply chains in the achievement of the strategic objectives, where countries, industries, and companies implementing the developments of industry 4.0 in their supply chains would achieve a significant competitive advantage and revolutionize industries, redefining product \& service availability, cost reduction and increase of market share. At the same time, Industry 4.0 is an industrial approach based on three fundamental principles. The first one is interoperable equipment and processes maximizing autonomous operations and integration (horizontal and vertical) across the entire supply chain. The 
second one is the digitalization of products and services. Finally, innovation and digital business models (Bauernhansl et al., 2014).

Automation, digitalization, integration across manufacturing processes, intelligent networking, intelligent logistics, intelligent factories, allow information sharing, flexibility, and customization of the product. High-level collaborative production technologies are incorporated into modern supply chains through SCM 4.0, resulting in optimized decision making. Enabling procurement control systems could improve the procurement efficiency and reduce the procurement cost. Intelligent production could enhance the efficiency of enterprise management services including enterprise inventory management, quality management, and labour utilization. Smart technologies enable tracking of raw materials, components, semifinished products, and finished goods in real-time. Availability of real-time data reduces error rates, allows tracking of product quality while intelligent logistics optimize the storage modes, transportation routes, etc. Smart systems could learn and solve their problems by themselves, improving the efficiency and reducing expenses of modern supply chains.

The modern trend of manufacturing supply chains is a robust collaboration with suppliers and their important partners as it enables the balance between demand and supply while generating a competitive advantage. Further, collaboration among partners in the supply chain allows an on-time product or service delivery, minimizes procurement lead time, and enables just-in-time production (Tarigan et al., 2021). Developments of industry 4.0 applicable to supply chain \& logistics and distribution help satisfy several strategic objectives of an organization, such as increasing efficiency, productivity of the production process, improving the quality of materials, finished goods, and service delivery process. Hence, it is noticeable that modern Industry 4.0 technologies play a crucial role in increasing performance \& realizing strategic objectives of SCM, logistics \& distributions Management \& Information Technology. Industry $4.0 \&$ its potential developments will lead to improvements in every area $\&$ business process in every organization, where those that adapt and implement the effects of Industry 4.0 in organizational processes will remain strong in a globally competitive market (Tarigan et al., 2021).

According to recent literature, implementing industry 4.0 developments in a typical supply chain requires further investments, studies, and additional technology development. However, investments and efforts by the government are also needed to overcome challenges regarding legislation. Effects of industry 4.0 concepts have increased the performance of supply chains in terms of three primary areas, such as efficiency, quality, and optimizing the routines (Logistics \& 
distribution). Those increments of quality increase the efficiency and optimizations of logistics \& distributing routines are also known as strategic objectives of Supply chain management (Strandhagen et al., 2017; Tarigan et al., 2021). Subsequently, to achieve the strategic objective of supply chain management, the role-played Industry 4.0 has not been explored so far. Not only that, but also interconnection among three Supply Chain strategic objectives in Industry 4.0 era has not been identified. Therefore, the two main research objectives of this study are as follows.

RO1. To explore the role played by Industry 4.0 to achieve efficiency, quality, and optimization of routines in the Supply Chain process.

RO2. To explore interconnectivity among strategic objectives of supply chain process among Industry 4.0 era.

\section{METHODS}

The main purpose of this study is to identify the role of Industry 4.0 developments on strategic objectives of supply chain management. Among several strategic objectives, this study considers only three strategic objectives enhance the quality of the whole supply chain, improve efficiency \& optimize the logistics $\&$ distribution routines. These identifications were assembled using a rigorous literature review. Within this study, 30 different articles based on the study area were categorized based on the potential three areas such as quality improvement, efficiency improvement, \& optimizations of logistic \& distribution routines. To identify the relevant articles, databases such as Scopus, Emerald Insight, Google Scholar, and Jstor belong to different journals from various disciplines were used. In selecting relevant articles, the year of publication was considered and is from 2011 to 2021. Keywords such as Industry 4.0, supply chain management, strategic objectives, quality enhancement, improve efficiency, optimization of logistic routines \& optimization of distribution were used in the keyword search.

\section{LITERATURE REVIEW \\ 3.1 Industry 4.0 \& quality enhancement}

The fourth industrial revolution has created new capabilities, new skills \& new resources for business organizations in terms of quality improvement. It will increase the efficiency of the production process, improve the quality of the final products, speed the delivery of the product or service to target customers \& quickly collect feedback from the target market (Sanders et al., 2016). In terms of the strategic objective of quality improvement in supply chains, thousands of concepts, models \& frameworks have been established over the last few decades to help managers of organizations enhance the value of tasks \& processes. The quality improvement attempt of managers could be quality assurance or quality management or quality assurance, or business excellence. 
Within these three quality aspects, quality frameworks such as ISO 9001 Quality Management International Standards, continues improvements such as Lean, Six Sigma \& Lean Six Sigma, business excellence tools such as European Foundation for Quality Management EFQM, the MBNA (EUA), or the Deming (Japan) models or awards are included. Quality tools, practices \& frameworks help ensure suitability (Fonseca \& Domingues, 2018). In other words, there is a positive relationship between economic, social \& environmental sustainability and best quality practices among the supply chains of organizations (Siva et al., 2016). ISO 9001:2015 aims at satisfying the customer and relevant stakeholders, complementing and reinforcing environmental management systems (for example, ISO 14001). Concepts such as Lean and Kaizen tend to decrease wastage of business processes simultaneously, improving organizational performance in terms of sustainability. Several quality techniques and tools such as Quality Function Deployment (QFD) and Design of Experiments aim to increase sustainability practices of business organizations in the supply chain process. Using the abovementioned tools, Mangers can identify the requirements of customers, design \& develop the product or services. Those processes can be evaluated to measure the sustainable influences with its' potential alternatives. Guidelines of the Deming Prize (2018) view the concept of quality as providing benefits and value with little or no harm to society and the environment. The European Foundation for Quality Management (EFQM) 2020 business excellence model incorporates the United Nations Sustainable Development Goals (SDGs) and European values that support business ethics. Quality management emphasizes improvement (continuous and disruptive) (Fatorachian \& Kazemi, 2021).

Quality has risen to become a crucial factor for the supply chain performance of organizations in the present digital transformation era due to Industry 4.0. In the process of adapting to \& implementing Industry 4.0, several tools \& models can be adopted, combined with quality management, information technology \& digitalization to create value for customers \& take competitive advantage among rivalries in the sense of quality enhancement task in Industry 4.0 adoption (Küpper et al., 2019; Sony et al., 2020; Vial, 2019). Quality enhancement in Industry 4.0 consists of quality of process \& quality of the product. Within a supply chain, they are considered to increase productivity \& satisfy customer requirements ultimately. But also, within the process of Industry 4.0 practices, planning, organizing, implementing \& evaluating should be considered (Delić et al., 2014).

Conversely, intelligent sensors, automation, and big data can support Statistical Process Control 
(SPC) or Six Sigma at the process level or provide data for high-level Total Quality Management (TQM) and business excellence models. Simultaneously, big data and analysis can be applied to the identification \& prevention of defects in the supply chain process of a specific business organization. It could be done using an accurate \& proper data analyzing plan (Fei \& Qinglin, 2017). The research encompassing quality and Industry 4.0 is comparatively scarce. Authors have focused on customers, quality, Lean, Industry 4.0, quality scorecards, quality management, and Industry 4.0, or, more recently, quality as a strategy for Industry 4.0 adoption (Fatorachian \& Kazemi, 2021). Therefore, by combining traditional quality management approaches and tools with Industry 4.0 approach, business organizations can enhance the accuracy of the TQM techniques.

The Industrial Internet of Things will lead to a faster and more effective business process, given its ability to clinically segregate defects in the supply chain process. It will lead to the maintenance of quality by preventing defects and saving resources of the organization (Illa, Kumar, \& Padhi, 2018). Further, Cloud computing will lead to integrations at all levels, increasing process \& task interoperability, realtime data availability \& information sharing among the supply chain functions, thereby enhancing the performance of supply chains on a large scale (Illa \& Padhi, 2018). In the scope of quality in Industry 4.0, there are several plausible technologies in addition to the above. Some of them are cyberphysical systems, artificial intelligence (Tarigan et al., 2021). Blockchain, simulation, modeling, visualization technology (augmented and virtual reality), automation and industrial robots, and additive manufacturing (Peres et al., 2019).

Without the concept of quality, the supply chain of a business organization in the context of Industry 4.0 is useless as the absence of which directly impacts the flexibility and productivity of supply chains. There is a firmly established relationship between the performance of business organizations \& the quality concept. To mitigate risks in the future, managers should pay attention to quality \& operations performance with digital transformations. Quality \& digital processes should be integrated within the supply chain as quality provides body knowledge (Consisting of models, theories, systems, tools \& techniques) to manage changes \& implications brought about by developments of industry 4.0 in supply chains. Combining Information \& Communication Technology \& digital transformation with machines \& products will create Industry 4.0.

On the other hand, technology is a crucial factor for the digital transformation process in Industry 4.0; simultaneously, several models $\&$ tools are needed for quality. This quality concept is an essential factor for winning customers in the supply chain process of the organization. 
Finally, both circuital elements should be performed successfully to maintain a smooth flow of business processes (Küpper et al., 2019; Sony et al., 2020). In other words, it will lead to delivering the right product or service in terms of reaching at the right time, at the right cost in the right condition (quality) to the right customer.

\subsection{Industry 4.0 \& optimization of logistics \& distribution}

In this modern business era, most organizations have focused on the supply chain of their organization \& how to manage organizations' supply chain to take competitive advantage. Subsequently, logistics \& distribution \& their routines, which are a part of an organization's supply chain while play a vital role. Due to the developments of industry 4.0, tools such as cyber-physical systems are available for resource planning \& management procedures. Specially, it helps to increase the productivity, flexibility of the overall supply chain system. With the proper forecasting of resources (people, materials, equipment) and increasing the visibility and transparency of the process, we can level up the efficiency of supply chains (Wee et al., 2015). Finally, it will lead to minimize the unnecessary routines from suppliers to plant. In other words, optimize the routines of organizations' supply chain.

In the sense of the warehouse, it is the hub of the SCM system. Nowadays, it plays a remarkably challenging role as it adapts to future requirements and newly introduced technical methods of smart warehouse management systems (Schrauf \& Berttram, 2016). As the development of industry 4.0, intelligent warehouse management systems have incorporated RFID tags using sensor technology to find the location of each transporter, using which the warehouse management systems can communicate with the transporter and allocate them to the correct destination point (distribution center/ warehouse) and predict arrival time according to the current traffic, weather, etc., and select proper docking slots, select gate-in, and gate-out locations, optimizing time constraint simultaneously. When pallets are moved from the assigned area, it automatically updates the current availability of the warehouse management systems stocks on time. As an advantage of the automated warehouse management systems updates, warehouse managers can take actions in advance to control out-of-stock situations. Consequently, it will lead to optimizing the distribution efforts $\&$ resources that have been allocated for the distribution function.

Further, organizations' transportation management system plays a crucial role in SCM because it is connected to transportation logistics and deals with order management systems and distribution centers or warehouses. The development of Internet of Things with a transportation management system can create communication networks between customers, trade partners, and 
carriers. The transportation management system can assess realtime and inline data resulting in the efficiency and effectiveness of Logistics 4.0. Using RFID tags with sensor technology and GPS technology ensures product tracking, fix shipping conditions, facilitate identification of product loading and unloading, significantly reducing time with the interaction of intelligent transportation systems. Few outcomes of the automated transportation management system are safer transport, fuel consumption, and pollution (Barreto et al., 2017; Skapinyecz et al., 2018). Currently, most industries are adopting the transportation management system and increasing service using cloud services and cloud computing. Transportation management system with cloud bases is found to be the upcoming the standard. A well-defined and configured transportation management system with interactive Internet of Things devices called a Smart transportation management system is a turning point of the SCM's towards flexible and efficient Logistics 4.0 operations (Qin et al., 2013).

Further, the intelligent transportation system is a new field of transportation systems such as transportation management, control, infrastructure, operations, policies, and control methods. Smart transportation system's essential for increasing safety and reliability, travel speeds, traffic flow, and reducing risks, accidents rate, carbon emissions, and air pollution. On the other hand, an intelligent transportation system provides cooperation solutions and a reliable transport platform. The most recent generation of the smart transportation system, generation 4.0, uses multimodal systems incorporating personal mobile devices, vehicles, infrastructure, and information networks for system operations and unique contextual mobility solutions (Factors \& Its, 2012). Intelligent transportation systems play an essential role with cooperative systems technologies to support and enhance the logistic process and the effectiveness of the fleet to substantially improve the results of the transportation community economically, in addition to sustainability. Consequently, combining typical warehouse, logistics \& distributions tools \& practices with modern industry 4.0 concepts \& tools tends to reduce the unnecessary vehicle routines \& distribution costs involved with the early era.

\subsection{Industry $4.0 \&$ efficiency}

To achieve strategic supply chain objectives, firms should have suppliers who emphasize cost reduction, improvement in quality, process flexibility, delivery reliability, use of technology, and commitment towards achieving supply chain objectives. Generally, performance measurement is defined as quantifying the effectiveness and efficiency of an action (Jajja et al., 2011). The consideration of sustainability as a strategic objective in supply chain management; Sustainable SCM suggests that the contribution of 
developments related to Industry 4.0 in increased sustainable industrial value creation will be remarkable in the future. Through recent literature, aspects in a supply chain such as efficient resource allocation, which includes water, energy, raw material, and other products, based on data that is collected in real-time are considering sustainability as a strategic objective of SCM resulting in new sustainable green practices (Chalmeta \& Santos-deLeón, 2020). Industry 4.0 suggests broad communication among different supply chain components, such as companies, factories, suppliers, logistics, resources, and customers (Barreto et al., 2017). Each of them optimizes its configuration in realtime depending on the demands and status of the subsequent links in its supply chain, which will allow the incorporation of sustainable practices and the realization of strategic objectives in SCM efficiency (Barreto et al., 2017; Martínez-Olvera \& Mora-Vargas, 2019).

After the industry 4.0 revolution, the demand for high-quality products and services is gradually increasing. According to the requirement, inbound and outbound logistics must be flexible with this new environment. The continuous high demand due to these developments cannot be fulfilled with primary planning and control practices (Barreto et al., 2017; Müller et al., 2015). The combination of innovative logistics and applications of the Cyber-physical systems and smart services and smart products called "Logistics 4.0" therefore becomes imperative. Intelligent services and smart products can get involved with the supply chain processes with more intelligence and automatic processes than employees, services, and products could, as logistics 4.0. Using the Internet, logistics 4.0 systems build a real-time communication platform between machines and humans. An efficient and strong Logistics 4.0 must consider the following technological applications such as resource planning systems, warehouse management systems, transportation management systems, intelligent transportation systems, and information security systems.

The literature found that such developments in information technology are to be adopted to overcome challenges posed due to increased complexities in supply chains concerning industry 4.0. Therefore, the combined use of digitalization and automation of Industry 4.0 together with big data technology is found to have great potential to overcome some of the problems affecting sustainable SCM and to achieve the strategic objectives of modern SCM and increase efficiency at various levels (Fatorachian \& Kazemi, 2021). Big data analytics and related advancements in data analytics allowing the acquisition of intelligence and the extraction of unknown, hidden, valid, and valuable relationships, patterns, and information are identified to be heavily associated with the developments of industry 4.0 applications (Siva et al., 2016). With 
cloud computing and big data, enterprises can accurately gain insights into customers' purchase frequency and preference, use dynamic pricing strategies, allocate shelf capacity, and optimize product adjustment to maximize product sales.

\section{DISCUSSION}

Importantly, this study has attempted to recognize the role played by Industry 4.0 on Supply Chain strategic objectives separately. Firstly, quality is considered as one of the strategic objectives which hope to achieve through higher performance. The present digital transformation era is adapting \& implementing tools that engage within quality management. Techno intelligent sensors, automation, and big data for traditional statistical process control or six sigma techniques. They are further, Using the Internet of Things, able to clinically segregate defects in the supply chain process. Through technologies such as Cloud technology, Artificial intelligence, Blockchain, Simulation and modeling, Visualization technology (augmented and virtual reality), Automation and industrial robots, and Additive manufacturing hoped to achieve process \& task interoperability, real-time data availability \& information at all levels of the supply chain. In the end, it will be able to function the supply activities of the supply chain smoothly, identify the defects earlier, and respond to the defects safely. In the end, quality will be achieved.
Secondly, in transport, logistics \& warehouses in the supply chain, RFID tags use sensor technology to predict arrival time according to the current traffic and weather. GPS technology ensures product tracking, fix shipping conditions, facilitate identification of product loading and unloading. Further, intelligent transportation system increases travel speeds, traffic flow and for reducing risks, accidents rate. Consequently, it will lead to optimizing time constraints, enhance the logistic process and the effectiveness of the fleet. Finally, hoped to achieve the third strategic objective of optimizing the logistic function of the supply chain. Thirdly, in this dynamic environment, enterprises can capture honest customer feedback. Logistics 4.0 will lead to high demand regularly. Usage of smart services and intelligent products is subjected to more intelligence and automatic processes than employees. Concerning the above positive factor, parties in the supply chain can access accurate insights, reduce cost \& process flexibility. Finally, it would be able to achieve the third strategic objective of supply chain performance called efficiency. This study explored how tools \& systems of Industry 4.0 will lead to achieve the three strategic objectives of SCM separately. Consequently, the findings answer the first research question.

Further, this study associate and extends prior Industry 4.0 literature research by proposing a model representing the interconnectivity among strategic objectives (quality, 
optimized routines \& efficiency) of the supply chain process in the Industry 4.0 era. The findings of this study revealed that separate tools \& systems in Industry 4.0, which led to achieve quality enhancement, can be used to achieve efficiency of the Supply Chain as well. Because of attaining quality, finally, it will lead to achieve efficiency as well. Subsequently, through the quality tool in the industry, utilize to achieve quality enhancement, Subsequently, utilize to achieve efficiency. At the same time, separate tools \& systems in Industry 4.0, which led to optimize logistics $\&$ distribution routines, can be used to achieve efficiency of the supply chain as well. Because of optimizing routines, finally, it will lead to achieve efficiency as well. Subsequently, through the optimization tools in Industry 4.0, utilize to optimize routines, Subsequently, utilize to achieve efficiency. Finally, conclude that using Industry 4.0 devices accomplishes the first two strategic objectives called quality enhancement \& optimizations of routines. Subsequently, it will lead achieve a third strategic objective called efficiency. In achieving the research objectives, the results of this paper, based on a model developed from the rigorous literature review, replicates earlier findings on Industry 4.0 and three strategic objectives of SCM.

\section{MANAGERIAL IMPLICATIONS}

The present study explored how the techniques of Industry 4.0 will lead to achieving the three strategic objectives of SCM separately. Despite the importance of Industry 4.0 for strategic objectives of SCM, the present study makes a vital contribution by developing a model on how the interconnection between the strategic objectives of the supply chain in the industry 4.0 era happens. Hence, this paper provides a better understanding of how to influence industry 4.0 techniques for achieving strategic objectives of SCM. The study revealed that after achieving objectives of quality enhancement and optimization of logistics and distribution, it will lead to achieve the third objective of efficiency. Further, using the proposed model of this study indicated the mentioned linkage between the strategic objective of the supply chain in the industry 4.0 era. Consequently, the findings of this study provide valuable insight to top managers \& information \& technology managers when they are going to adapt available Industry 4.0 techniques for achieving different strategic objectives of the supply chain. There can identify which tool is suitable for attaining which objective \& linkage exist among three objectives in Industry 4.0 era.

\section{LIMITATIONS \& FUTURE RESEARCH DIRECTION}

The study is expected to assist scholars in relevant research areas in literature analysis and research gap identification. Importantly, this study only considers three strategic objectives: enhancing quality, optimizing logistics \& distribution routines, \& increase efficiency. 
However, there are several other strategic objectives of SCM as well. Some build competitive advantages, create a set of value to the end customer, and optimize the plant capacity. Consequently, it is more worth exploring how tools \& systems of Industry 4.0 influence to achievement mentioned strategic objectives as well. Further, this study is not limited to any industry or sector. Considering the supply chain of apparel, hotel \& tourism, rubber manufacturing, a supermarket chain with Industry 4.0 concept would be able to exposure $\&$ identify more specific \& unique behaviors \& patterns. Subsequently, suggest considering mentioned industry or sector in future studies. When engaged with a concept such as Industry 4.0, it will create challenges in the areas of security and privacy where risks associated with improper data acquisition, leakage and unauthorized disclosure of information, and insertion of malicious software. Therefore, considering such threats, how influence to achieve strategic objective parallelly while implementing the tools \& systems of Industry 4.0.

\section{CONCLUSION}

The study presented in this paper presents an analytical review of recent literature in Industry 4.0 and SCM to link the effects of Industry 4.0 on strategic objectives of SCM. Within this study, a total of 30 different articles based on the study area were reviewed. It was identified that the aspects of quality improvement, the efficiency of supply chains, transport, and logistics are heavily impacted due to the developments of industry 4.0 concepts within supply chains in the modern age. Industry 4.0 \& its potential consequences will lead to improvements in every area \& business process in every organization. Those that adapt and implement the developments of Industry 4.0 in organizational processes and supply chains will remain strong in a globally competitive market. Within this study indicated \& revealed that how tools \& systems of Industry 4.0 will lead to achieve the three strategic objectives of SCM separately. Further, using the proposed model of this study indicated the linkage between the strategic objective of the supply chain in the industry 4.0 era. 


\section{APPENDIX}

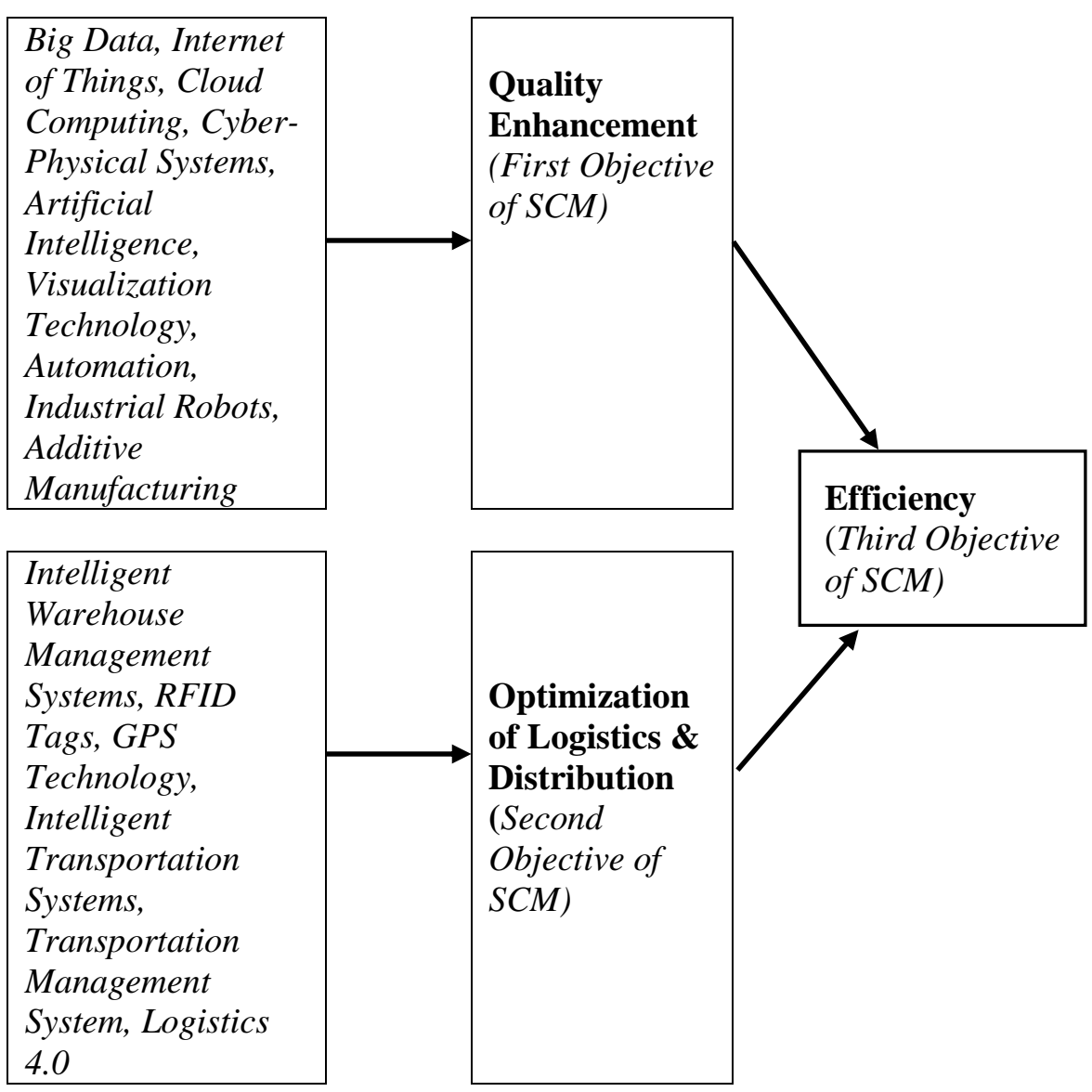

Figure 1.1: Interconnection between Identified Three Strategic Objective of SCM in Industrial 4.0 Era. 


\section{REFERENCES}

Barreto, L., Amaral, A., \& Pereira, T. (2017). Industry 4.0 implications in logistics: an overview. Procedia Manufacturing, 13, 12451252.https://doi.org/10.1016 /j.promfg.2017.09.045

Bauernhansl, T., Diegner, B., Diemer, J., \& Dümmler, M. (2014). Industrie 4.0whitepaper fue-themen.

Carvajal Soto, J. A., Tavakolizadeh, F., \& Gyulai, D. (2019). An online machine learning framework for early detection of product failures in an Industry $4.0 \quad$ context. International Journal of Computer Integrated Manufacturing, 32(4-5), 452465.https://doi.org/10.10 80/0951192X.2019.157123 8

Chalmeta, R., \& Santos-deLeón, N. J. (2020). Sustainable supply chain in the era of industry 4.0 and big data: A systematic analysis of literature and research. Sustainability (Switzerland), 12(10).https://doi.org/10.33 90/su12104108

Delić, M., Radlovački, V., Kamberović, B., Vulanović, S., \& Hadžistević, M. (2014). Exploring the impact of quality management and application of information technologies

on organisational performance the case of Serbia and the wider region. Total Quality
Management and Business Excellence, 25(7-8), 776789.https://doi.org/10.1080/ 14783363.2014 .904566

Factors, D., \& Its, I. (2012). Review of Existing Literature and Deployment Tracking Surveys Decision Factors Influencing ITS Adoption 1.1.1.1.1.1 www.its.dot.gov/index.htm Final Report-April 2012 Publication Number: FHWA-JPO-12-043.

April.www.its.dot.gov/index .htm

Fatorachian, H., \& Kazemi, H. (2021). Impact of Industry 4.0 on supply chain performance. Production Planning and Control, 32(1), 63-81. https://doi.org/10.1080/0953 7287.2020 .1712487

Fei, T., \& Qinglin, Q. (2017). New IT driven service-oriented smart manufacturing: framework and characteristics. IEEE Transaction on Systems, Man and Cybernetics, 49(1), 81-91. https://doi.org/10.1109/TS MC.2017.2723764.

Illa, P. K., \& Padhi, N. (2018). Practical Guide to Smart Factory Transition Using IoT, Big Data and Edge Analytics. IEEE Access, 6, 55162-55170.

https://doi.org/10.1109/AC CESS.2018.2872799

Jajja, Sadiq, M. S., Brah, S., \& Hassan, S. (2011). Impact of 
strategic supply chain management on organizational performance. Proceedings of the 40th Annual Meeting of Western Decision Sciences Institute.

Küpper, D., Knizek, C., Ryeson, D., \& Noecker, J. (2019). Quality 4.0 takes more than technology.

Martínez-Olvera, C., \& MoraVargas, J. (2019). A comprehensive framework for the analysis of Industry 4.0 value domains. Sustainability (Switzerland), 11(10), $1-21$. https://doi.org/10.3390/su11 102960

Müller, I. J. P., Ketter, W., Kaminka, G. ., Wargner, G., \& Bulling, N. (2015). A multiagent system perspective on industry 4.0 supply networks. Systems Technologies.

Peres, R. S., Barata, J., Leitao, P., \& Garcia, G. (2019). Multistage Quality Control Using Machine Learning in the Automotive Industry. IEEE Access, 7, 7990879916.https://doi.org/10.110 9/ACCESS.2019.2923405

Qin, E., Long, Y., Zhang, C., \& Huang, L. (2013). Cloud computing and the internet of things: Technology innovation in automobile service. Lecture Notes in Computer Science (Including Subseries Lecture Notes in Artificial Intelligence and Lecture Notes in Bioinformatics),
8017 LNCS(PART 2), 173180.https://doi.org/10.1007/ 978-3-642-39215-3_21

Sanders, A., Elangeswaran, C., \& Wulfsberg, J. (2016). Industry 4.0 implies lean manufacturing: Research activities in industry 4.0 function as enablers for lean manufacturing. Journal of Industrial Engineering and Management, 9(3), 811833.https://doi.org/10.3926/ jiem. 1940

Schrauf, S., \& Berttram, P. (2016). Industry 4.0: How digitization makes the supply chain more efficient, agile, and customer-focused. Strategy \&Technology.

Siva, V., Gremyr, I., Bergquist, B., Garvare, R., Zobel, T., \& Isaksson, R. (2016). The support of Quality Management to sustainable development: a literature review. Journal of Cleaner Production, 138, 148157.https://doi.org/10.1016/ j.jclepro.2016.01.020

Skapinyecz, R., Illés, B., \& Bányai. (2018). Logistic aspects of Industry 4.0. IOP Conference Series: Materials Science and Engineering, 448(1), 0-11. https://doi.org/10.1088/1757 $-899 X / 448 / 1 / 012014$

Sony, M., Antony, J., \& Douglas, J. A. (2020). Essential ingredients for the implementation of Quality 4.0: A narrative review of literature and future directions for research. $T Q M$ 
Journal, 32(4), 779793.https://doi.org/10.1108/ TQM-12-2019-0275

Strandhagen, J. W., Alfnes, E., Strandhagen, J. O., \& Vallandingham, L. R. (2017). The fit of Industry 4.0 applications in manufacturing logistics: a multiple case study. Advances in Manufacturing, 5(4), 344-358. https://doi.org/10.1007/s404 36-017-0200-y

Tarigan, Z. J. H., Mochtar, J., Basana, S. R., \& Siagian, H. (2021). The effect of competency management on organizational performance through supply chain integration and quality. Uncertain Supply Chain Management, 9(2), 283294.https://doi.org/10.5267/ j.uscm.2021.3.004

Vial, G. (2019). Understanding digital transformation: A review and a research agenda. Journal of Strategic Information Systems, 28(2), 118-144.

https://doi.org/10.1016/j.jsis .2019.01.003

Wee, D., Kelly, R., Cattel, J., \& Breunig, M. (2015).Industry 4.0-how to navigate digitization of the manufacturing sector. McKinsey \& Company. 